\title{
Analysis of the thermal heating of poly-Si and a-Si photovoltaic cell by means of Fem
}

\author{
G. Acciani, O. Falcone and S. Vergura \\ Dipartimento di elettrotecnica ed elettronica \\ Politecnico di Bari \\ Via E. Orabona 4, 70100 Bari (Italy) \\ Phone/Fax number:+39 080 5963590, e-mail: acciani@poliba.it, falcone@deemail.poliba.it, vergura@deemail.poliba.it
}

\begin{abstract}
The aim of the paper is to propose the tridimensional model of a photovoltaic cell implemented in Comsol Multiphysics environment, a finite element method (FEM) based software. The analysis of the thermal behaviour of the implemented model has been conducted to simulate the behaviour of the device under operating conditions. The model has been implemented according to the geometrical and physical features of commercial photovoltaic cells. Two technologies have been considered: poly and amorphous silicon based cells. The implemented model has also been validated from an electrical point of view. Simulation results confirm the goodness of the proposed model for the thermal behaviour of PV cells.
\end{abstract}

\section{Key words}

Photovoltaic, cell, finite element method, model.

\section{Introduction}

The study in depth of the thermal behaviour of photovoltaic devices may be considered as a critical aspect in the diffusion of photovoltaic conversion systems. Anomalies in the distribution of the temperature on the cell under operating conditions, parameter defined by NOCT (Nominal Operative Cell Temperature) specification, may lead to an important decrease of the performances of the cell from an electrical and efficiency point of view [1]-[2]. As the efficiency of these devices is low (11-14\% for the polycrystalline cells and less than $8 \%$ for the a-Silicon ones), its reduction may be detrimental for the performances of the whole conversion plant. . Also the electrical parameters are strongly influenced by the temperature increasing: the open circuit voltage (VOC) decreases when temperature increases while the short circuit current (ISC) shows only slight variation [3]. Finally, fill factor and output power of the PV cell are strongly influenced by the temperature variations [4-5].The scope of this paper is the analysis, using a Finite Element Method (FEM) approach, of the thermal behaviour of solar devices. A 3D model of the two different typologies of photovoltaic cells has been implemented using the CAD module available in Comsol environment. The structure is squared and obtained by the superposition of different layers with different thickness [6]. Libraries for physical settings allow defining the physical features of each layer. A large computational power has been required for the simulations, because of the complexity of the implemented model from a numerical point of view. A dual core architecture equipped with $16 \mathrm{~GB}$ of ram has been been used and only direct solvers have been used to solve the model. PARDISO (sPARse DIrect Solver) has shown to be the most performing, as expected [7]. The paper is organized as follows: section 2 concerns the development of the proposed model, section 3 introduces the electrical and the thermal analysis with simulation results and the effect of Joule's and radiative heating at the same time, finally section 4 reports conclusions.

\section{Proposed models}

Two different models has been developed because the amorphous silicon cell structure is obtained through the superposition of more layers with respect to the polycrystalline one. The last one has been developed maintaining the setting as exposed in [6]. The monocrystalline layer has been replaced with the poly-Si one, whose specific thermal parameters (thermal conductivity, specific heat and density) are available in Comsol's material libraries. Figure 1 reports the zoom on the thickness of the implemented amorphous Silicon cell.

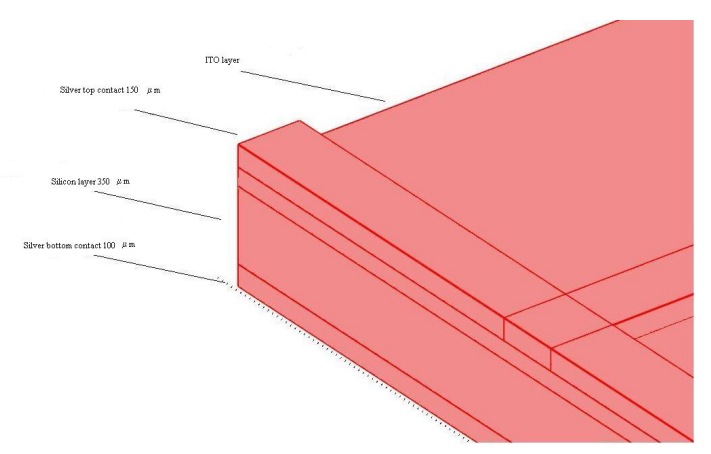

Fig. 1. Zoom on the thicknesses of the a-Si modelled cell. 
In the figure the upper layer, the top electrode of the cell has been implemented as to be composed of silver as well as the bottom plate and their thicknesses are respectively $150 \mu \mathrm{m}$ and $100 \mu \mathrm{m}$. The ITO (Indium Thin Oxide) layer has a specific layer of $85 \mu \mathrm{m}$. Its small thickness imposes the choice to set up the mesh size to Extra coarse to avoid problems of empty space generation that may occur with so small thickness when the mesh size is reduced. Finally for the silicon layer a thickness of $350 \mu \mathrm{m}$ has been set up. Physical features have been loaded from available material libraries.

To complete the model definition the physical features of each layer have to be set up. The value of thermal conductivity or specific heat has to be set for the thermal analysis, while the value of the electrical conductivity has to be imposed for the electrical one. Each metallization has been modeled with silver. Using Comsol's Material Library (MEMS Material Properties section Metals) it is possible to load all specific features of the chosen material. Silicon features have been loaded from Basic Material Properties library while oxide characteristic parameters have been loaded from the Material Library, Simplex Oxides.

\section{Simulative analysis}

This section proposes the simulation results for the thermal analysis and the electrical validation of the proposed model. For each analysis, a brief summarization of the specific parameters and boundary settings is presented. The thermal analysis has been developed using the Comsol's Heat transfer module while the electrical validation has been done using the $\mathrm{AC} / \mathrm{DC}$ module.

\section{A. Thermal analysis}

The values of the thermal parameters required in the setting mask for the poly-Si and the a-Si models are reported in tables I and II, respectively.

Table I. Thermal parameters for the poly-Si model.

\begin{tabular}{|l|c|c|c|}
\hline Material & $\boldsymbol{k}\left[\mathbf{W} /\left(\mathbf{m}^{*} \mathbf{K}\right)\right]$ & $\rho\left[\mathbf{k g} / \mathbf{m}^{3}\right]$ & $\boldsymbol{C}_{\boldsymbol{p}}\left[\mathbf{J} /\left(\mathbf{k g} \mathbf{g}^{*} \mathbf{K}\right)\right]$ \\
\hline $\mathrm{Ag}$ & 429 & 10500 & 235 \\
\hline $\mathrm{Poly}-\mathrm{Si}$ & 34 & 2320 & 678 \\
\hline $\mathrm{TiO}_{2}$ & $\mathrm{k}(\mathrm{T}[1 / \mathrm{K}])[\mathrm{W} /(\mathrm{m} * \mathrm{~K})]$ & $\operatorname{rho(T[1/K]}\left[\mathrm{kg} / \mathrm{m}^{3}\right]$ & $\mathrm{C}(\mathrm{T}[1 / \mathrm{K}])[\mathrm{J} /(\mathrm{kg} * \mathrm{~K})]$ \\
\hline
\end{tabular}

Table II. Thermal parameters for a-Si model.

\begin{tabular}{|c|c|c|c|}
\hline Material & $k\left[\mathbf{W} /\left(\mathbf{m}^{*} \mathbf{K}\right)\right]$ & $\rho\left[\mathbf{k g} / \mathbf{m}^{3}\right]$ & $C_{p}\left[\mathrm{~J} /\left(\mathrm{kg}^{*} \mathrm{~K}\right)\right]$ \\
\hline $\mathrm{Ag}$ & 429 & 10500 & 235 \\
\hline ITO & 87 & 7120 & 753 \\
\hline $\mathrm{a}-\mathrm{Si}$ & $\mathrm{k}(\mathrm{T}[1 / \mathrm{K}])[\mathrm{W} /(\mathrm{m} * \mathrm{~K})]$ & $\operatorname{rho}(T[1 / \mathrm{K}])\left[\mathrm{kg} / \mathrm{m}^{3}\right]$ & $\mathrm{C}(\mathrm{T}[1 / \mathrm{K}])[\mathrm{J} /(\mathrm{kg} * \mathrm{~K})]$ \\
\hline
\end{tabular}

Note that the parameters of the $\mathrm{TiO}_{2}$ layer (for poly-Si model) and the parameters of a-Si layer (for a-Si model) are defined as a temperature-dependent equation. The mathematical model of Neuman's boundary condition on the total flux to be set up on the model is expressed in (1) and is valid for both the models:

$$
\mathbf{- n} \bullet \mathbf{q}=\mathrm{q}_{0}+\mathrm{h}\left(\mathrm{T}_{\text {cell }}-\mathrm{T}\right)+\sigma \varepsilon\left(\mathrm{T}_{\text {env }}{ }^{4}-\mathrm{T}^{4}\right)
$$

where $\mathrm{q}_{0}$ is the incoming flux, $h$ the heat transfer coefficient that depends on geometrical structure of the model. The heat transfer coefficient $h$ is the factor that links the heat swapped for convection between a solid and the fluid lapping it and the difference between the temperatures of the fluid and the solid, according to the well known Newton's equation (2):

$Q=h A\left(T_{s}-T_{0}\right)$

where $\mathrm{Q}$ is the total heat transfer, $\mathrm{A}$ is the heated surface area, Ts the surface temperature and $T_{0}$ the mean temperature of the fluid. It has been computed equal to $11 \mathrm{~W} / \mathrm{m}^{2} \mathrm{~K}$ for both the models, $\mathrm{T}_{\text {cell }}$ and $\mathrm{T}_{\text {env }}$ the initial temperature of the cell and the environment temperature, $\sigma$ the Stefan-Boltzmann constant and $\varepsilon$ the emissivity of each material (Table III). The values of $\mathrm{q}_{0}, \mathrm{~T}_{\text {cell }}$ and $\mathrm{T}_{\text {env }}$ are defined by the NOCT specification which states that with an incoming flux of $800 \mathrm{~W} / \mathrm{m}^{2}$, a wind speed of 1 $\mathrm{m} / \mathrm{s}$ and an environmental temperature of $20^{\circ} \mathrm{C}$, the cell temperature is $45{ }^{\circ} \mathrm{C}$ for the poly-Si cell and $50{ }^{\circ} \mathrm{C}$ for the amorphous one with a tolerance of two degrees in both cases.

Table III. Emissivity values.

\begin{tabular}{|l|c|}
\hline Material & $\boldsymbol{\varepsilon}$ \\
\hline $\mathrm{Ag}$ & 0.01 \\
\hline $\mathrm{Poly}-\mathrm{Si}$ & 0.85 \\
\hline $\mathrm{a}-\mathrm{Si}$ & $0.83-0.96$ \\
\hline $\mathrm{TiO}_{2}$ & 0.9 \\
\hline & \\
$\mathrm{ITO}$ & 0.9 \\
\hline
\end{tabular}

The simulations of both models behaviour have been solved developing a steady state analysis in Comsol environment Heat transfer model.

Numerically the models are similar: for the poly-Si case the mesh has been generated using a pre-defined Extra Coarse mesh size, resulting into 356982 elements corresponding to 570578 degrees of freedom. The number of degrees of freedom defines the number of linear equations to be solved for the modelled problem. In the a-Si case the mesh has been generated with the same element size of the above mentioned case: 140893 elements have been generated, corresponding to 351230 degrees of freedom.

Figures 2 and 3 report the simulation results for the former case while figure 4 concerns the latter one. 


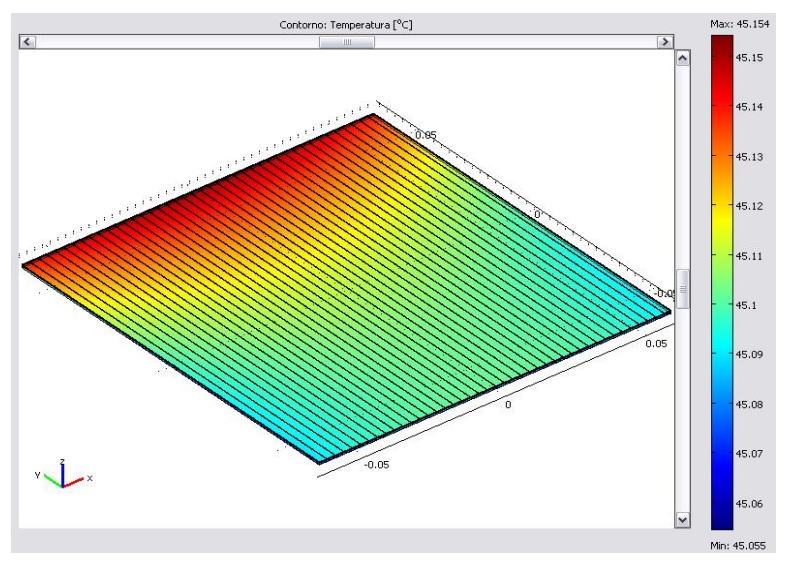

Figure 2. Temperature distribution on the upper face of the poly-Si cell.

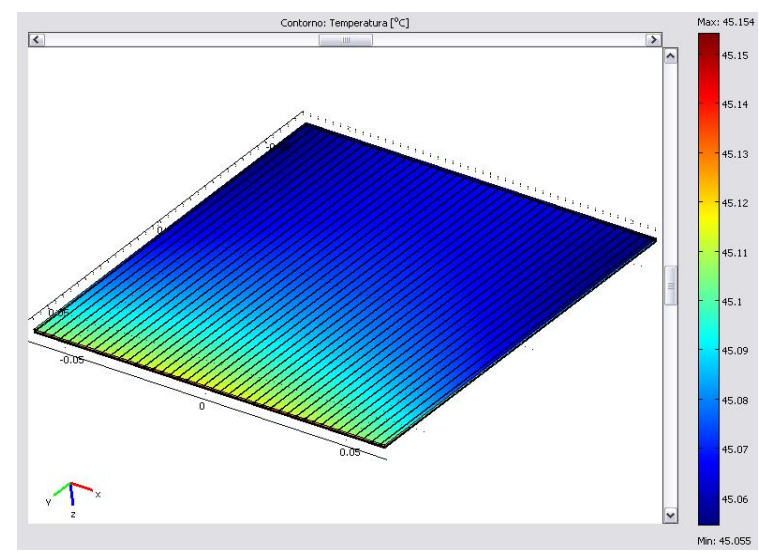

Figure 3. Lower face of the poly-Si cell.

The simulation results for the poly-Si cell in terms of temperature show that the model reaches a temperature of about $45{ }^{\circ} \mathrm{C}$, showing a small temperature difference between upper and lower face.

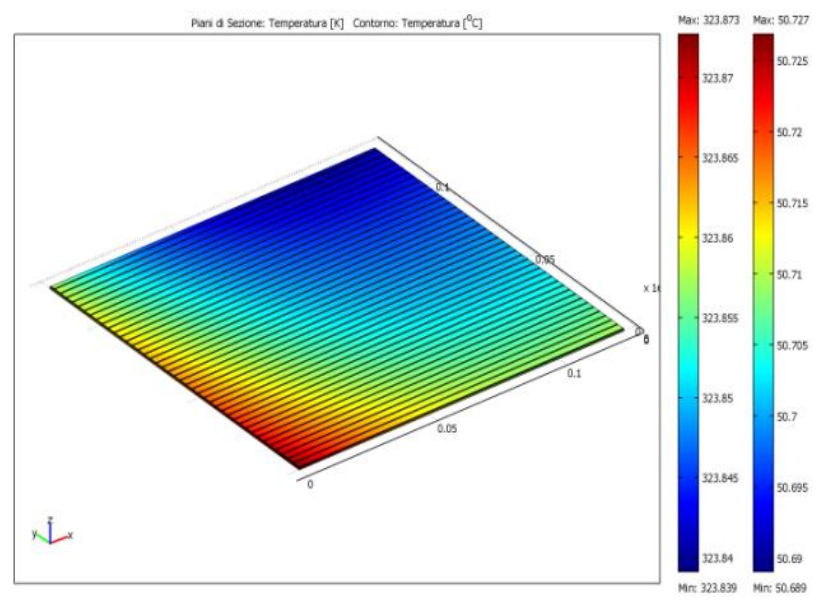

Figure 4. Front face temperature distribution for the a_Si cell.

The a-Si cell reaches the temperature of about $50{ }^{\circ} \mathrm{C}$, according to NOCT.

The small temperature difference between upper and lower face, where the incoming flux value has been set up to $0 \mathrm{~W} / \mathrm{m}^{2}$, confirms the goodness of the proposed model that shows a temperature distribution quite similar to the real operating case.

\section{B. Electrical validation}

To validate the model from an electrical point of view, each cell model has been connected to a RC parallel bipolar component to simulate the behaviour of the solar device as a current source (Figure 5).

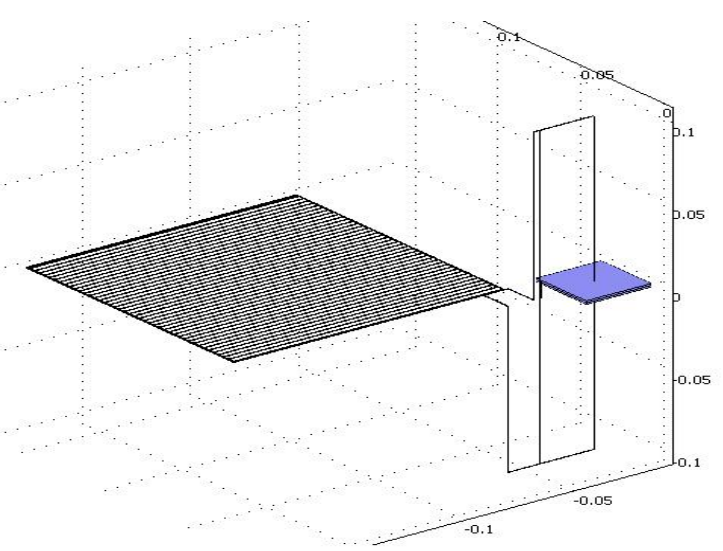

Figure 5. Modeled PV-Cell connected to the bipolar circuit.

The values of capacity and resistance fix the value of the time constant of the circuit. Also in this case the simulation results are reported only for the a-Si case. According to the value of $\mathrm{R}(10 \Omega)$ and $\mathrm{C}\left(5 \times 10^{-10} \mathrm{~F}\right)$ the time constant of the circuit is equal to $5 \times 10^{-10}$ seconds. The voltage across capacitor pins reaches the final value after $2.5 \times 10^{-9}$ seconds as it is confirmed in figure 6 .

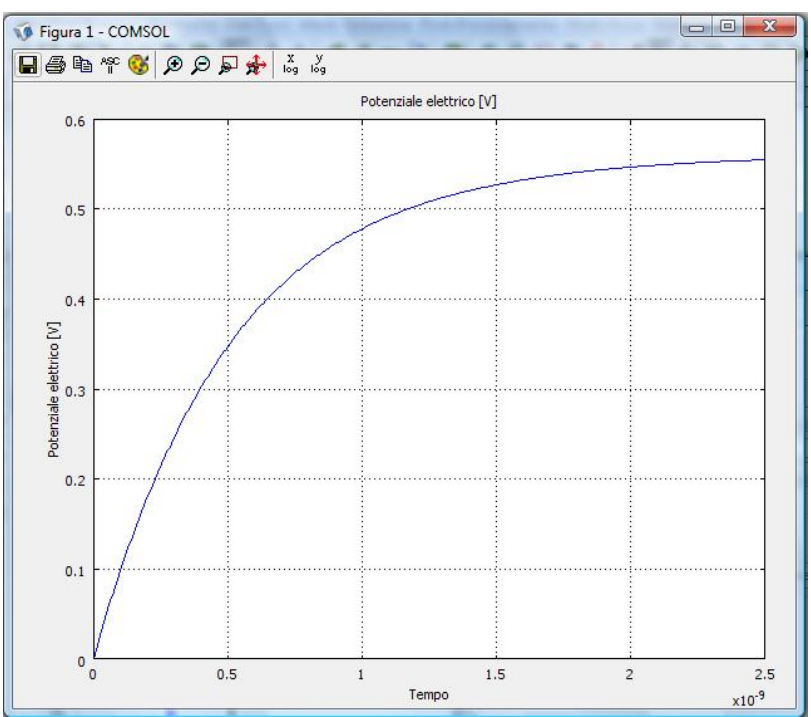

Figure 6 . Time domain voltage for the capacitor pin.

The simulation has been run using a transient state analysis setting the time constraints as follows:

- beginning $\mathrm{t}=0$

- final time $\mathrm{t}=5 \tau$ 
- $\quad$ simulation steps: two orders lower than $\tau$.

A boundary condition of incoming current flux has been imposed on the cell surface directly connected with the RC bipolar component. In this case the model implemented by Comsol is shown in equation (3).

$-\mathbf{n} \cdot \mathbf{J}=J_{n}$

where $J_{n}$ is the value of the current density.

The goodness of the imposed boundary condition is confirmed by the flux line plotting: red lines show the direction of the current flowing trough the conductor into the bipolar circuit (Figure 7).

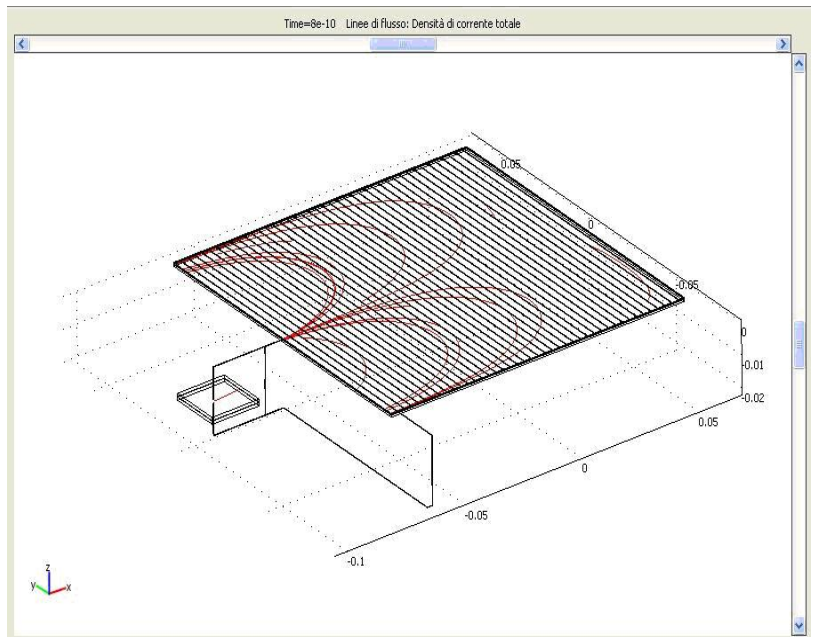

Figure 7. Flux lines plot.

Numerically it is important to highlight that a simple RC circuit added to the PV cell leads to an important increase of the complexity of the system from a numerical point of view. The number of mesh elements and the degrees of freedom increase strongly, using an extra coarse mesh size. The mesh has been generated with Extra coarse size, obtaining 473.501 elements and 798.535 degrees of freedom. This resulting into an increasing of the time required to solve the models. The electrical model has been solved for the poly-Si case in 840 seconds, four times the thermal model. Simulation time for the amorphous case is of about 800 seconds. All simulation have been run under the direct solver PARDISO; the RC circuit causes an important increase of the simulation time.

\section{Thermo electrical modelling}

The heating of a photovoltaic cell under operative conditions is strongly due to the effect of sun irradiation. The effect of the Joule's heating induces a lower increasing of the cell temperature with the respect to the radiative one. To improve the goodness of the proposed model the behaviour of the same under different conditions has been simulated. Table IV reports simulation results. $T_{0}$ represents the first temperature of the cell, $\mathrm{T}_{\mathrm{f}}$ the temperature reached after the heating and, finally, the last field reports the temperature increasing.
Table IV. Cell under different operative conditions.

\begin{tabular}{|l|c|c|c|}
\hline & $\mathbf{T}_{\mathbf{0}}$ & $\mathbf{T}_{\mathbf{f}}$ & $\Delta \mathrm{T}$ (increasing) \\
\hline Radiative flux & $20^{\circ} \mathrm{C}$ & $39^{\circ} \mathrm{C}$ & $19^{\circ} \mathrm{C}$ \\
\hline Joule's effect & $20^{\circ} \mathrm{C}$ & $28^{\circ} \mathrm{C}$ & $8{ }^{\circ} \mathrm{C}$ \\
\hline $\begin{array}{l}\text { Radiative flux and } \\
\text { Joule's effect }\end{array}$ & $20^{\circ} \mathrm{C}$ & $48^{\circ} \mathrm{C}$ & $28^{\circ} \mathrm{C}$ \\
\hline
\end{tabular}

Simulation results highlight as for the proposed model the Joule's effect heating produces a lower heating of the cell with respect to the radiative case, as expected.

The system shows a quasi-linear behaviour.

The following figure 8 shows simulation result for the third case considered, i.e. cell under both heat source. Note as the hottest part of the system is the load, implemented with a thin conductive layer.

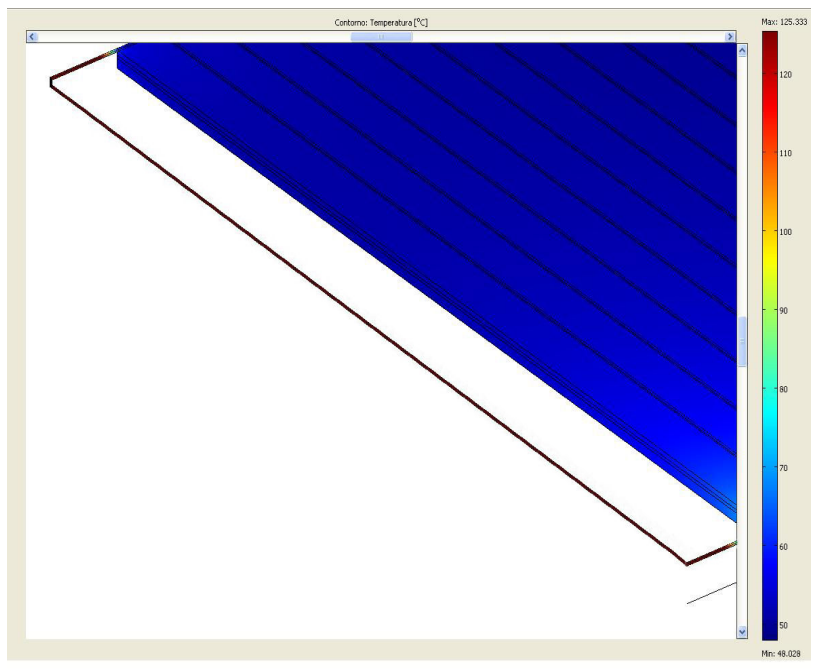

Figure 8 . Temperature distribution on the cell under both heat sources.

\section{Conclusion}

The paper proposes the 3-D FEM model for a PV-cell, implemented into a devoted software. Simulation results agree with experimental results on real PV cell in terms of temperature distribution in operating condition. The proposed model of a well-operating PV-cell can be useful for implementing typical defects usually pointed out by means of thermo-graphy.

\section{References}

[1] D. Menes-Rodrìguez, P. P. Horley, J. Gonzàlez-Hernàndez, Y. V. Vorobiev, P. N. Gorley, "Photovoltaic solar cell performance at elevated temperatures", Solar energy, 243-250, 2005.

[2] E. Skoplaki, J. A. Palyvos, On temperature dependence of photovoltaic module electrical performances: A review of efficiency/power correlations, Solar energy, 83,614-624, 2009. 
[3] H.A. Zondag, 2007. Flat-plate PV-thermal collectors and systems - a Review, Renew. Sustain. Energy Rev. doi:10.1016/j.rser.2005.12.012.S.

[4] D. Menes-Rodrìguez, P. P. Horley, J. Gonzàlez-Hernàndez, Y. V. Vorobiev, P. N. Gorley, 2005, "Photovoltaic solar cell performance at elevated temperatures", Solar energy, 243-250.

[5] E. Skoplaki, J. A. Palyvos, 2009, On temperature dependence of photovoltaic module electrical performances: A review of efficiency/power correlations, Solar energy, 83,614624.

[6] S. Vergura, G. Acciani, O. Falcone, "3-D PV-cell Model by means of FEM", IEEE-ICCEP, Capri, Italy, 9th-11th June 2009, pp.35-40.

[7] O. Schenk, K. Gärtner, and W. Fichtner, Efficient sparse LU factorization with left - right looking strategy on shared memory multiprocessors, BIT, 40(1), pp. 158 - 176, 2000. 